
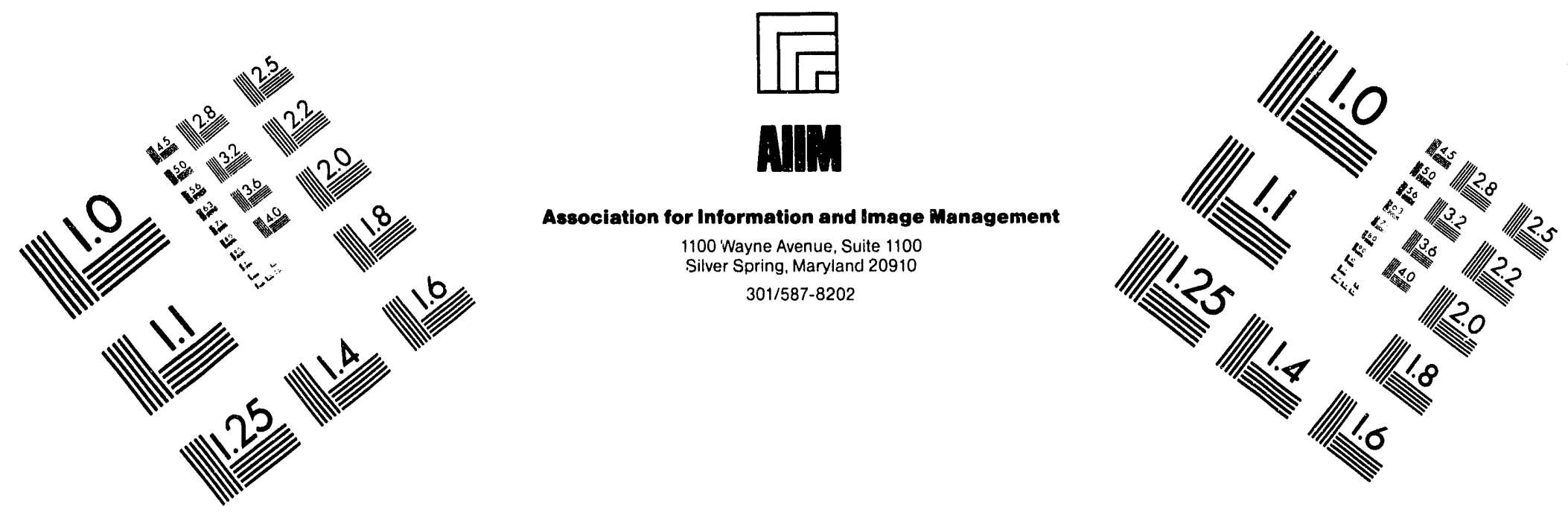

\title{
Centimeter
}

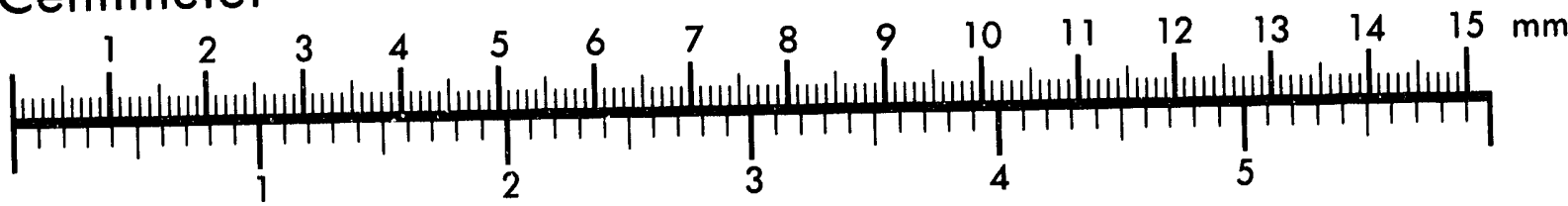
Inches
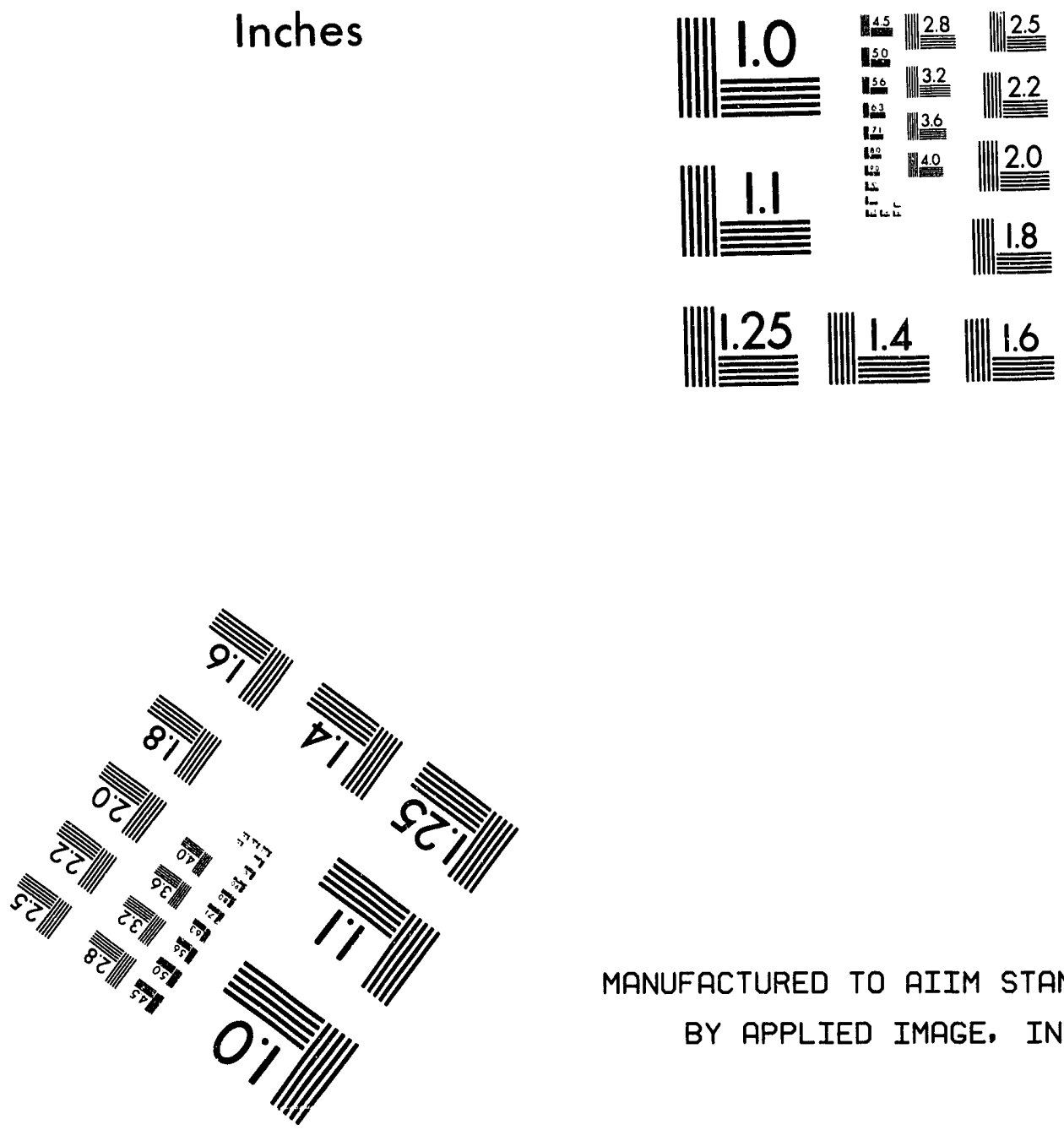

MANUFACTURED TO AIIM STANDARDS

BY APPLIED IMAGE, INC.

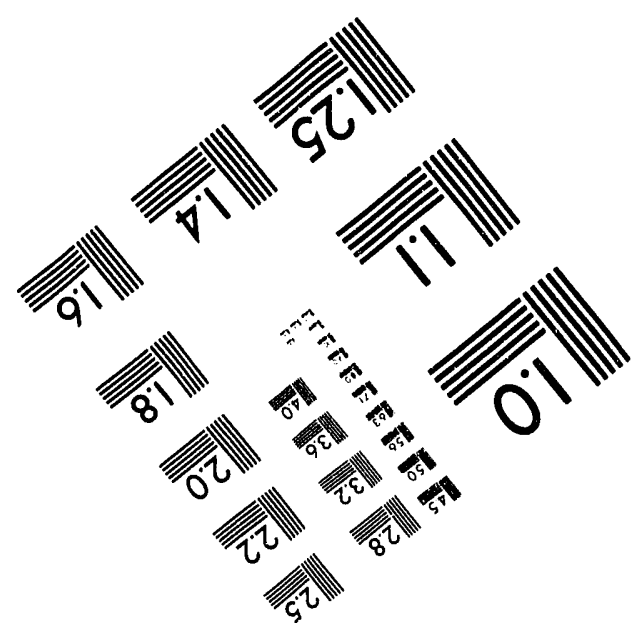



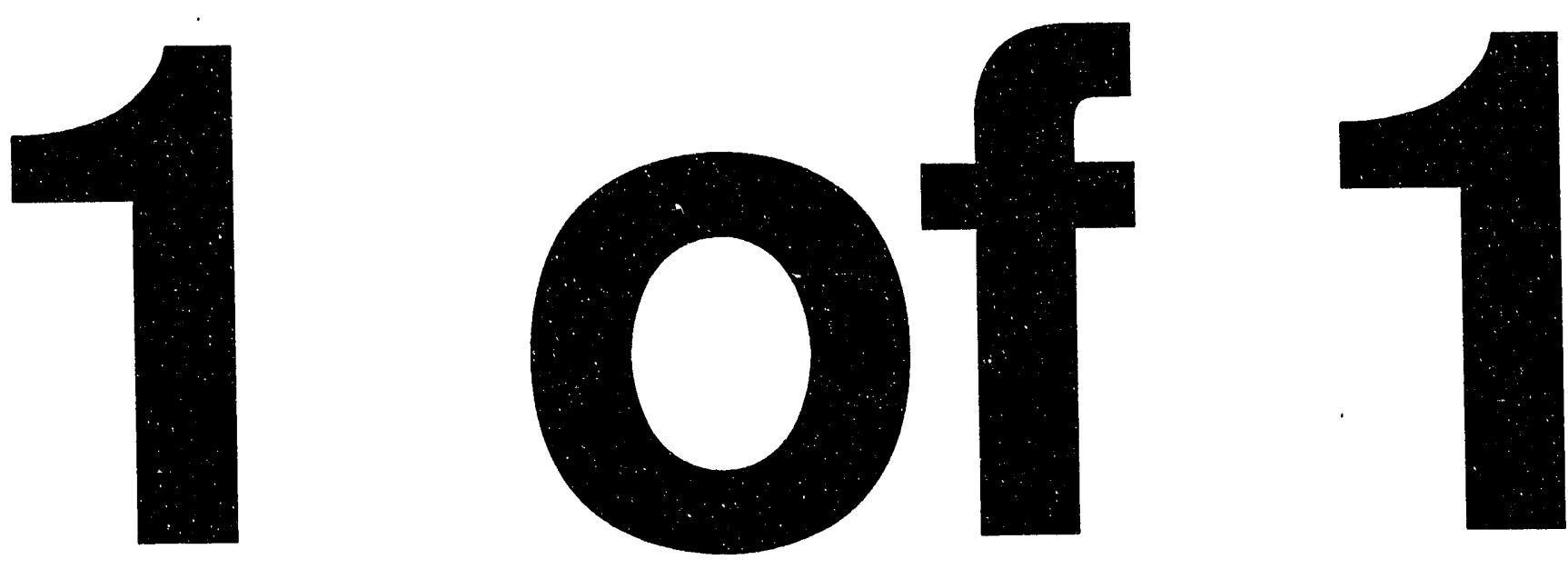
EGG-EELS-10666

\section{Software Quality Assurance Plan for PORFLOW-3D}

Steven J. Maheras

Published March 1993

Idaho National Engineering Laboratory EG\&G Idaho, Inc. Idaho Falls, Idaho 83415

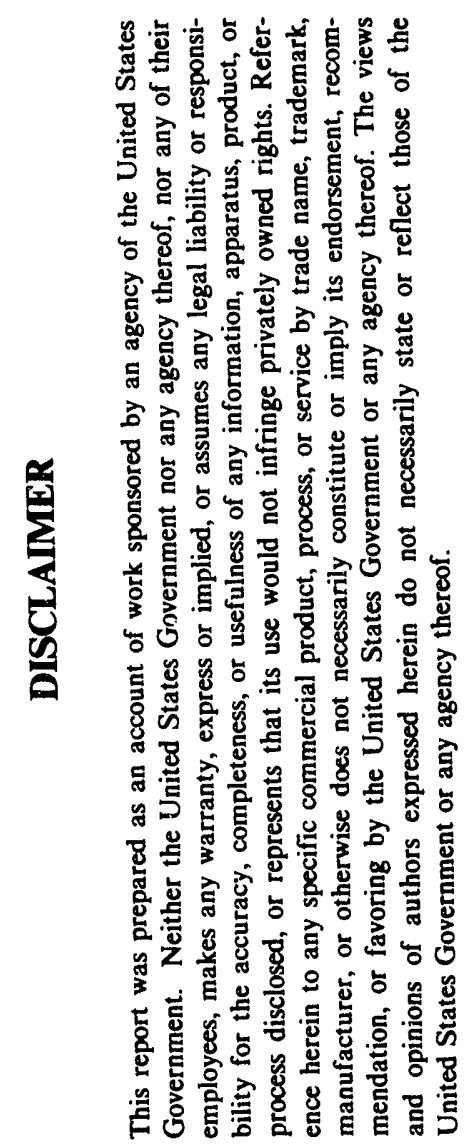

Prepared for the

U.S. Department of Energy

Office of Environmental Restoration and Waste Management Under DOE Savannah River Field Office Contract DE-AC09-89SR18035 Through DOE Idaho Field Office Contract DE-AC07-76ID01570 
SOFTWARE QUALITY ASSURANCE PLAN FOR PORFLOW-3D

Prepared By: $\frac{S L}{\text { Steven J. Maheras }}$

Date: Februmy 2,1993

Reviewed By: $\frac{\operatorname{Kog}_{\text {Rogen }} R_{\text {Reitz }} \text { Seitz }}{2 / 2 / 93}$ Date:

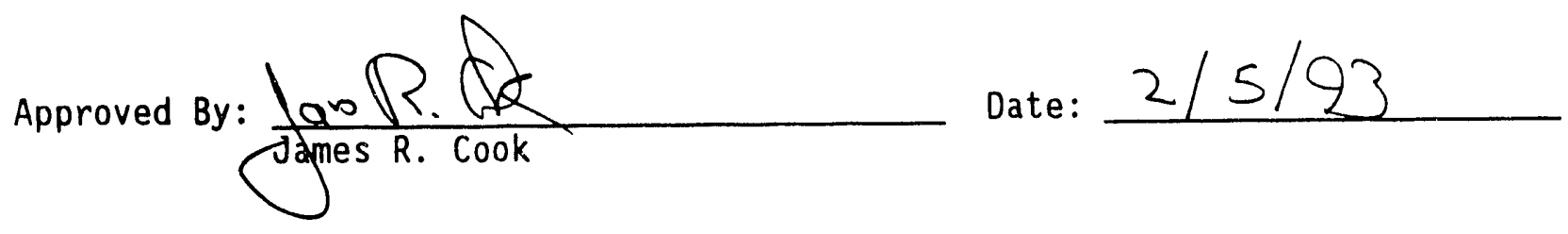

Approved By: 
This plan describes the steps taken by the Idaho National Engineering Laboratory Subsurface and Environmental Modeling Unit personnel to implement software quality assurance procedures for the PORFLOW-3D computer code.

PORFLOW-30 was used to conduct radiological performance assessments at the Savannah River Site. Software quality assurance procedures for PORFLOW-3D include software acquisition, installation, testing, operation, maintenance, and retirement. Configuration control and quality assurance procedures are also included or referenced in this plan. 


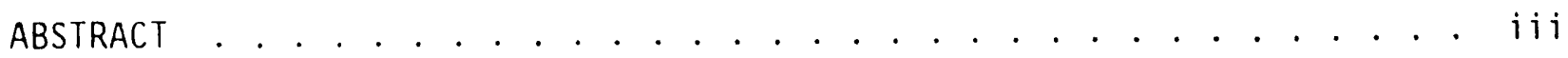

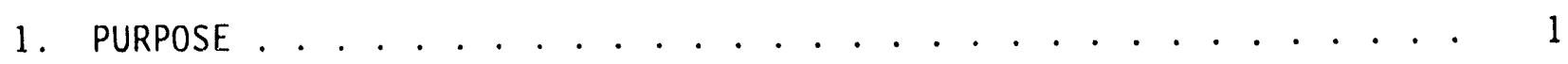

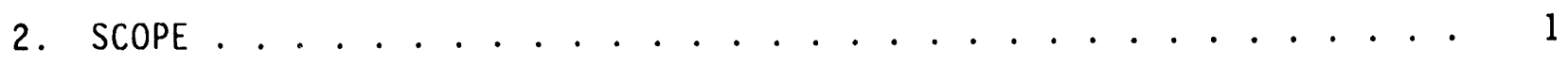

3. TERMS AND DEFINITIONS . . . . . . . . . . . . . . . . 1

4. RESPONSIBILITIES FOR SQA ..................... 2

5. SOFTWARE LIFE CYCLE .................. . . 3

5.1 Software Installation .............. 3

5.2 Software Testing. . . . . . . . . . . . 3

5.2 .1 Verification............. . . 3

5.2 .2 Validation or Benchmarking .......... 4

5.2 .3 Documentation of Testing . . . . . . . . . . . 4

5.3 Software Operation and Maintenance .......... 4

5.3 .1 Operation ................. 4

5.3.2 Maintenance .............. 4

5.4 Software Retirement ... . . . . . . . . . . 5

6. CONFIGURATION CONTROL ......................... 5

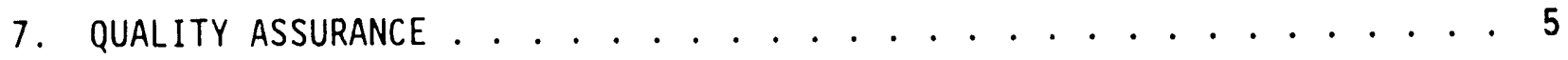

8. ERROR REPORTING AND CORRECTIVE ACTION .............. 6

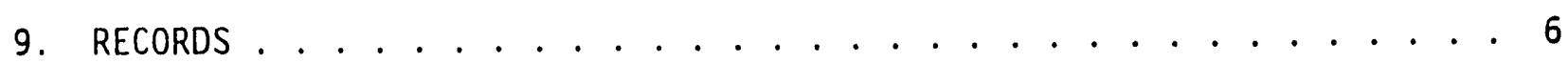

10. REFERENCES .......................... 7 


\section{SOFTWARE QUALITY ASSURANCE PLAN}

\section{FOR PORFLOW-3D}

\section{PURPOSE}

This plan describes the steps taken by the Idaho National Engineering Laboratory (INEL) Subsurface and Environmental Modeling (SEM) Unit personnel to implement software quality assurance procedures consistent with the EG\&G Idaho Quality Manual Section QP-21, "Computer Software Configuration Management," and ASME NQA-2a-1990 Part 2.7, "Quality Assurance Requirements of Computer Software for Nuclear Facility Applications," for the computer code PORFLOW-3D (Runchal and Sagar 1991).

\section{2. $S C O P E$}

The software quality assurance plan applies to life-cycle phases of PORFLOW-3D as it is used in conducting radiological performance assessments at the Savannah River Site (SRS) including acquisition, installation, testing, operation, maintenance, and retirement. Configuration control and quality assurance procedures are also included or referenced in this plan.

Other commercial software such as MATHEMATICA and spreadsheet, word processing, and graphics software that are distributed with executable code only are beyond the scope of this document in the areas of configuration control and testing. However, calculations performed using this software are still subject to formal documentation requirements.

\section{TERMS AND DEFINITIONS}

COMPUTER CODE CUSTODIAN - The designated individual with responsibility for coordinating the control of computer codes and related documentation.

CONFIGURATION CONTROL - Configuration control is the process of identifying and defining the configuration items in the PORFLOW-3D software system, controlling the release and change of these items throughout the system life cycle, and recording and reporting the status of configuration items and change requests. 
PERFORMANCE ASSESSMENT PRINCIPAL INVESTIGATOR - The principal investigator (PI) is the person having overall technical responsibility for the radiological performance assessment project.

PORFLOW-3D - PORFLOW-3D is a commercially-available computer code acquired by the INEL for use in simulating unsaturated and saturated flow and mass transport in the subsurface. Simulation results will provide concentrations of radionuclides originating the low-level waste facilities in ground water. By sponsor [Westinghouse Savannah River Company (WSRC)] directive, it is considered "High Impact" software (QAP-20-1, Rev 1., $10 / 01 / 90)$. This is equivalent to EG\&G Idaho Quality Level B software. ${ }^{2}$

SOFTWARE - Computer programs, procedures, associated procedure manuals, computer source code, and program disks.

SOFTWARE VALIDATION - Software validation refers to testing the accuracy of decisions or assumptions incorporated into the software.

SOFTWARE VERIFICATION - Software verification refers to testing the accuracy of numerical algorithms contained in the software.

\section{RESPONSIBILITIES FOR SOFTWARE QUALITY ASSURANCE}

PERFORMANCE ASSESSMENT PRINCIPAL INVESTIGATOR - The PI for the radiological performance assessments for which PORFLOW-3D was acquired is responsible for software quality assurance. Upon acquisition, the PI is responsible for overseeing that the software life-cycle procedures are correctly implemented and for overseeing configuration control and quality control procedures. The PI is also responsible for maintaining documentation of software quality assurance procedures. The PI may delegate the configuration control responsibility to the computer code custodian.

a. Quality Level B software failure would degrade the performance or reliability of operations, data acquisition, or deliverables. 


\section{SOFTWARE LIFE CYCLE}

\subsection{Software Installation}

Because PORFLOW-3D is preexisting, commercially available software, life-cycle steps associated with the development of the software are the responsibility of the computer code vendor. Installation will take place in accordance with the instructions provided by the PORFLOW-3D vendor. A backup copy of the original software shall be made and stored under version control. Because PORFLOW-3D is stored under version control on the INEL CRAY, it is protected against theft, loss, and environmental damage.

After installation, PORFLOW-3D will be installed in the INEL Version Control System (Miller et al. 1991). The INEL Version Control System provides for automated change control and logging; therefore, a separate configuration control logbook is not required.

\subsection{Software Testing}

Testing is required to confirm that PORFLOW-3D functions as the code vendors assert. Once installed, a FORTRAN analyzer is typically run on the code to look for potential programming errors. Marshall and Marwil (1991) contains a description of a typical FORTRAN analyzer. No programming errors were identified in PORFLOW-30.

\subsubsection{Verification}

The capabilities of PORFLOW-30 must be verified by comparing analytical solutions of the desired simulation equations for a defined problem to PORFLOW-3D output to evaluate the accuracy of numerical algorithms. Comparison of software simulation results with results from previously verified versions or codes (termed benchmarking) is acceptable. An independent verification of an earlier version of PORFLOW has been performed (Magnuson et al. 1990). 


\subsubsection{Validation or Benchmarking}

Validation of PORFLOW-3D requires data from SRS that are not available in sufficient quantity or quality to provide meaningful results. Therefore, PORFLOW-3D will be benchmarked by comparing PORFLOW-3D results to results obtained using other software that has gained high acceptability from acknowledged experts. An independent benchmarking of an earlier version of PORFLOW has been performed (Magnuson et al. 1990).

\subsubsection{Documentation of Testing}

The results of the verification and benchmarking of PORFLOW-3D are documented in Magnuson et al. (1990). The verification and benchmark testing of PORFLOW was conducted using Version 1. However, the version of PORFLOW used on this project was PORFLOW-3D. The test problems used to verify and benchmark Version 1 have been run using PORFLOW-3D and equivalent results were obtained.

\subsection{Software Operation and Maintenance}

\section{3 .1 Operation}

Operation of PORFLOW-3D will be conducted by personnel approved by the PI, who in the PI's judgment are appropriately trained. These individuals will have access to the user's manual of the code.

Operational tests will be performed whenever PORFLOW-3D is installed on a computer with a different operating system or when configuration changes are made to the software or hardware system.

\subsubsection{Maintenance}

Maintenance to correct software errors or adapt to changes in requirements or the operating environments will be made only with the PI's approval. However, the PI may delegate this authority to the code custodian. The changes will be logged in the Version Control System. Because the Version 
Control System provides an automated log of changes to the source code, no separate maintenance log will be required.

\subsection{Software Retirement}

Once the life cycle of PORFLOW-3D is over, it will be retired according to the code developer's requirements in order to ensure future use is in accordance with appiicable licensing agreements. All documents pertaining to the life cycle of PORFLOW-3D at the INEL will be archived. During the retirement phase of the software life cycle, the routine use of PORFLOW-3D will be prevented. The retirement procedures followed will be documented.

\section{CONFIGURATION CONTROL}

PORFLOW-3D is maintained under configuration control using the INEL Version Control system. The Configuration Management Plan for PORFLOW-3D is part of a larger Configuration Management Plan documented in Matthews (1992), which meets the requirements of the EG\&G Idaho Quality Manual, QP-21, "Computer Software Configuration Management."

\section{QUALITY ASSURANCE}

The PI shall periodically review the approach and assumptions and evaluate input data sets to ensure that quality assurance procedures liave been applied and that proper documentation is being generated throughout the life cycle of PORFLOW-3D. When necessary, the PI will call on others to review assumptions and input data to verify their appropriateness and accuracy.

Key assumptions (those critical to the project) will be evaluated by WSRC, Oak Ridge National Laboratory-Grand Junction (ORNL-GJ), and INEL; a consensus on each key assumption will be reached.

Project notebooks will be used to document day-to-day project activities. Formal documentation of analyses conducted using PORFLOW-3D will be accomplished using the EG\&G Idaho Engineering Design File (EDF) format. The EDF format provides for formal approvals of input data, assumptions, and output by the author, reviewer (technical), and approver (managerial) of the 
calculations. The EG\&G Idaho Quality Manual, "Design Control," QP-3, Section 4.2.15, describes the elements required in the documentation of a design analysis. The EDFs generated during this project will be transmitted to SRS as part of the project documentation.

\section{ERROR REPORTING AND CORRECTIVE ACTION}

Any errors found in the code will be reported to the code author and other affected organizations such as SRS and ORNL-GJ. The error and its corrective action will be documented in the project logbook maintained by the analyst.

\section{RECORDS}

The following documents will be retained as records that will be turned over to WSRC:

1. Software Quality Assurance Plan

2. The Version Control System change log for PORFLOW-30

3. Documentation of PORFLOW-3D, including user's manual

4. EDFs containing results generated using PORFLOW-3D

5. Project notebooks. 


\section{REFERENCES}

ASME NQA-2a-1990, Part 2.7, Quality Assurance Requirements of Computer Software for Nuclear Facility Applications.

EG\&G Idaho, Inc, 1992, Quality Manual, Sections QP-3, "Design Control," and QP-21, "Computer Software Configuration Management."

Magnuson, S. 0., R. G. Baca, A. J. Sondrup, 1990, Independent Verification and Benchmark Testing of the PORFLO-3 Computer Code, Version 1.0, EGG-BG-9175.

Marshal1, N. H. and E. S. Marwil, 1991, Cross Reference Analys is of FORTRAN (CRAFT), EGG-CATT-9198.

Matthews, S. D., 1992, Software Configuration Management Plan for Controlled Code Support System, EGG-CATT-10196.

Miller, G. V., D. G. Barber, E. S. Marwil, 1991, Software Quality Assurance Plan for the Version Control System, Release 2, EGG-CATT-9821.

Runchal, A. K. and B. Sagar, 1991, PORFLOW: A Model for Fluid Flow, Heat, and Mass Transport in Multifluid, Mult iphase Fractured or Porous Media; User's Manual - Version 2.34, Analytic and Computational Research, Inc., West Los Angeles, CA. 

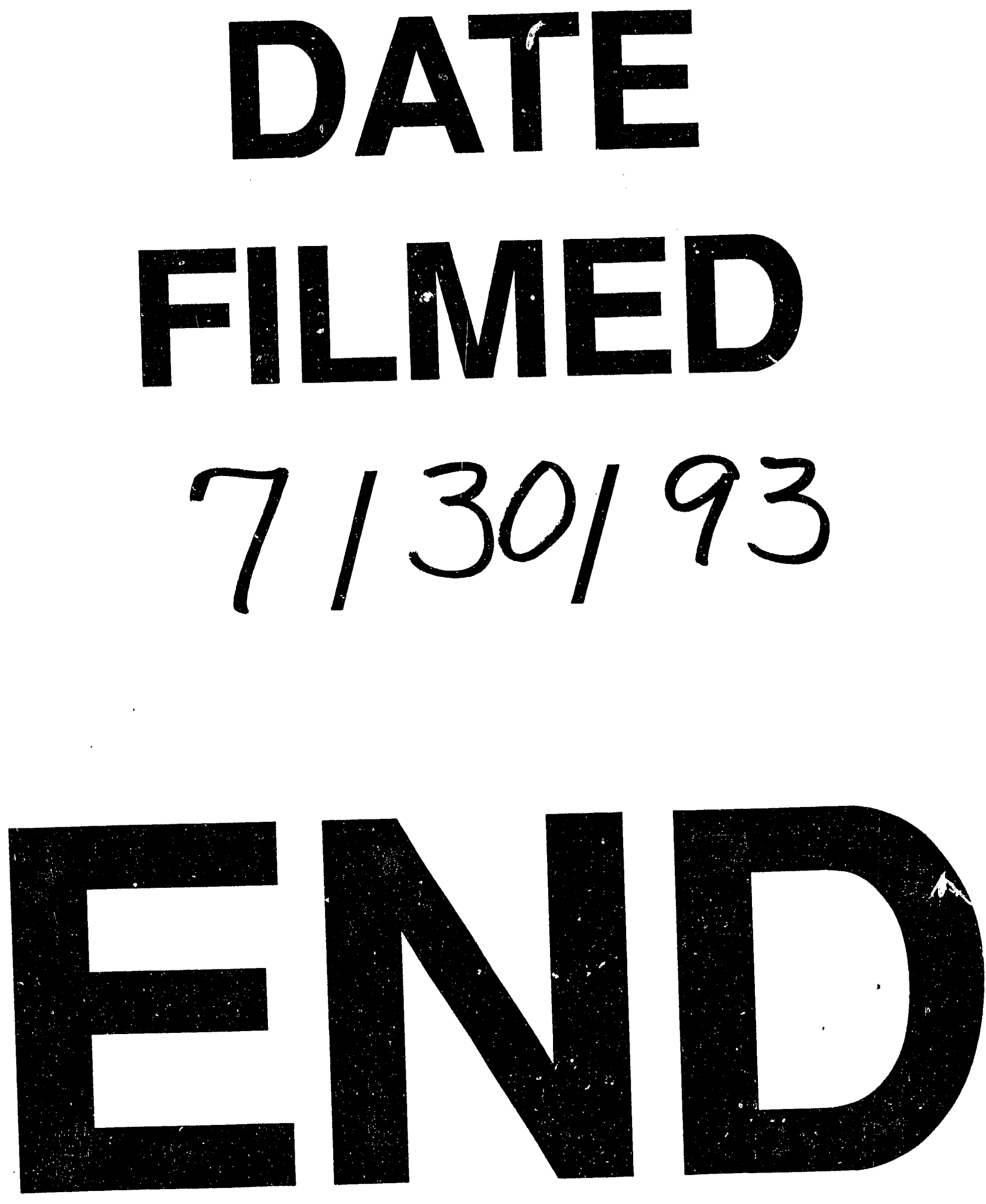
